\title{
From journal to headline: the accuracy of climate science news in Danish high quality newspapers
}

\author{
Gunver Lystbæk Vestergård
}

\begin{abstract}
A significant number of mass media news stories on climate change quote scientific publications. However, the journalistic process of popularizing scientific research regarding climate change has been profoundly criticized for being manipulative and inaccurate. This preliminary study used content analysis to examine the accuracy of Danish high quality newspapers in quoting scientific publications from 1997 to 2009. Out of 88 articles, 46 contained inaccuracies though the majority was found to be insignificant and random. The study concludes that Danish broadsheet newspapers are 'moderately inaccurate' in quoting science publications but are not deliberately hyping scientific claims. However, the study also shows that $11 \%$ contained confusion of source, meaning that statements originating from press material or other news outlets were incorrectly credited to scientific peer-reviewed publications.
\end{abstract}

\section{Context}

A sound public climate change debate depends on comprehensible information about scientific discoveries being available to policymakers and laymen. This is a task to be carried out by the mass media. However, the media has been accused of not getting the job done adequately. "The media have failed to inform the public," geographer Joe Smith concludes after a series of seminars on the BBC coverage of climate change. ${ }^{1}$ Others emphasize a sensationalistic, dramatizing, biased or inaccurate coverage. ${ }^{2,3,4}$ The criticism is further underlined by the counter reaction to the mass media popularization of climate science from the scientific community - e.g. the website www.realclimate.org or the campaign 'A guide to facts and fictions about climate change' launched by the British Society. ${ }^{5}$

Criticism of journalistic incompetence regarding science is historically rooted in the $19^{\text {th }}$ century rise of popular science. Fundamentally it stems from a cultural clash based on different ideals, structure, motives, procedures and norms. ${ }^{6}$ The scientific community relies on a set of internalized norms articulated in 1942 by Robert K. Merton in the essay 'The Normative Structure of Science' as the CUDOS norms (communalism, universalism, disinterestedness, originality and skepticism ${ }^{7}$ ). Journalism in Denmark on the other hand is founded on the news criteria called AVISK (topicality, essentiality, identification, sensation, conflict). ${ }^{8}$ In comparing the two a conflict of interest emerges. The scientific community endeavors to produce independent, objective and universal research whereas the news media require personal intrigues, subjectivity and drama. McInerney et al. (2004) describes it as a contradiction between the quantitative and rational mentality among scientists and the qualitative and emotional mentality among news media. ${ }^{9}$

As in all cultural divides mistrust and skepticism towards the counterpart is created. In this case it manifests itself in accusations of incompetence. ${ }^{10}$ But what is myth and what is fact? In other words, how accurately is the mass media in portraying science?

Even though it is an essential part of the science/media interaction, only a few scholars have researched the topic, ${ }^{11}$ which is academically linked to media studies, sociology of science and science communication.

Science news accuracy research comes out of American science journalism analysis of the 1970s and 1980 s. $^{12,13,14}$ Part of the background for this research was a growing critique from the scientific community that the mass media is mishandling scientific research. ${ }^{15}$ The essential finding of this work, however, is that science journalism is generally accurate, with most inaccuracies caused by omissions. ${ }^{16}$ 
The majority of the early research used the scientific sources themselves to identify inaccuracies. Thus, studies directly comparing media text quotations to scientific publications are scarce. With regards to climate change, the most notable example is Allan Bells quantitative analysis from 1994 including 321 press clippings from 1988 in New Zealand. By the use of six categories of inaccuracy (scientific/technical inaccuracies, non-scientific inaccuracies, significant omissions, exaggerations and distortions of emphasis) clippings were coded by the authors of the publications. Over $80 \%$ of the clippings were coded no worse than 'slightly inaccurate'. ${ }^{17}$

A similar study regarding GMO food was carried out by McInerney et al. in 2004. A comprehensive data set of press clippings from 18 American newspapers and magazines from 1992-2002 were examined. As Bell they discovered that only a minor fraction of the articles were faulty, but at the same time concluded that it only takes a few risk framed articles to change public perception of a scientific subject such as GMO food. They also coined the term 'broad brush approach' to describe the media's ability to "paint data as clear-cut factual information and leaving smaller details and subtleties of the research to more scholarly publications". 18

Similar conclusions have been made by Eldridge and Reilly in 2003 analyzing the coverage of mad cow disease in British media ${ }^{19}$ and Bubela and Caulfield in $2004 .{ }^{20}$ Both states that even though the majority of science news articles are loyal to the scientific claim - though simplifying them - it only takes a few distorting articles to alternate public perception on the subject.

The existing literature therefore points to the hypothesis that most of the generalized condemnation of the press coverage of science is baseless. However most studies of science accuracy have been carried out in English-speaking countries where the dominant media structure is a liberal or Anglo-American model associated with a high degree of professionalization and specialization of journalism. ${ }^{21}$ In smaller language areas, such as Denmark, journalists are more often generalist and therefore science reporters are few. For example only one (Dagbladet Politiken) of the three major national newspapers employs a science editor. $^{22}$ Also Rikke Schimdt Kjærgaard has argued that leaving out local cultural and national contexts in media studies leads to simplistic narratives of occurring trends. She based this assertion on her finding that, contrary to US and British press, Danish media coverage of nanotechnology was not increasingly negative. ${ }^{23}$ Moreover, inaccuracies are bound to occur from the fact that Danish science news based on scientific articles require translation from English. Therefore it is necessary to carry out separate investigations in such unique language zones as the Danish.

\section{Objective}

The main research question was as follows: How accurate are selected Danish nationwide high quality newspapers in quoting publications from Science and Nature regarding the topic climate change?

Based on the existing literature it was hypothesized that the newspapers would be fairly accurate though serious exaggerations and sensationalized claims were expected to emerge sporadically.

Also most inaccuracies were expected to be random as a result of editorial busyness and recklessness as opposed to systematic inaccuracies resulting from journalistic news values and readers appeal motives such as deliberately exaggerating or sensationalizing claims. The latter hypothesis is inspired by Maxwell T. Boykoff findings from 2007 concluding that British press is not influenced by the journalistic norm of 'balanced' reporting which would cause a bias coverage of climate change as climate skeptics are given a disproportionate amount a coverage. ${ }^{24}$

\section{Method}

Data was accumulated from the Danish media database Infomedia. Three nationwide high quality newspapers were chosen: Jyllands-Posten, Dagbladet Politiken and Dagbladet Information. Originally also tabloid newspapers were included but in order for articles to be included in the study, the scientific publication source needed to be identifiable. This was not possible for any climate change science articles covered in the tabloid press in the period. ${ }^{25}$ The journals Science and Nature were chosen because of their status as the most widely read and most prestigious scientific journals worldwide.

A number of test runs showed that news articles on climate change began rising steadily from 1997 and therefore a time period from 1997 to 2009 was chosen. All articles from uneven years including 'climate 
change*', 'global warming*' and 'greenhouse effect*' and quoting Science or Nature were extracted $(1997,1999,2001,2003,2005,2007$ and 2009) resulting in 88 news articles.

\begin{tabular}{|c|c|c|c|c|c|c|c|c|}
\hline Year & 1997 & 1999 & 2001 & 2003 & 2005 & 2007 & 2009 & Total \\
\hline $\begin{array}{l}\text { News articles quoting } \\
\text { Science/Nature }\end{array}$ & 8 & 7 & 6 & 8 & 26 & 17 & 16 & 88 \\
\hline $\begin{array}{l}\text { Total number of climate } \\
\text { change news articles }\end{array}$ & 253 & 166 & 443 & 308 & 528 & 1615 & 1609 & 4922 \\
\hline $\begin{array}{l}\text { Quoting articles in } \\
\text { percentage of total number }\end{array}$ & 3 & 4 & 1 & 3 & 5 & 1 & 1 & $2,6^{*}$ \\
\hline $\begin{array}{l}\text { Total Science/Nature articles } \\
\text { on climate change } \\
\text { Quoting articles per } \\
\text { newspaper }\end{array}$ & 348 & 437 & 649 & 607 & 763 & 1251 & 1552 & 5607 \\
\hline Dagbladet Politiken & 1 & 2 & 1 & 4 & 13 & 11 & 11 & 43 \\
\hline Dagbladet Information & 4 & 4 & 3 & 1 & 9 & 3 & 5 & 29 \\
\hline Jyllands-Posten & 3 & 1 & 2 & 3 & 4 & 3 & 0 & 16 \\
\hline
\end{tabular}

*Average per year

Table 1. Number of climate change news articles quoting Science/Nature per year per newspaper.

Identifying the corresponding scientific publications in Science and Nature required some detective work as none of the 88 articles included a complete title or other unambiguous markers.

The quantitative content analysis was based on Riffe et al.'s methodology dividing the data into units. ${ }^{26}$ 'Study units' were identified as news articles on climate change, 'sampling' units as the 88 articles quoting scientific publications, 'information units' as text paragraphs including quotes and 'referential units' as the scientific publications. Inspired by Bells typology of inaccuracies and based on a pilot coding test the following categories were identified to be used in the coding process:

1) Factual inaccuracies: E.g. inaccurate numeric values or scientific terms.

2) Confusion of source: Claims from press briefings or other news outlets wrongfully credited to the scientific publication.

3) Omissions/additions: Quotations added or lacking information which misleads the scientific claims.

4) Exaggerations: E.g. elevated numeric values or increased geographic area. Note that the distinction between factual inaccuracies and exaggerations is based on the textual context.

5) Paraphrases: Misleading use of paraphrases or euphemisms.

6) Faulty conclusions: Wrongful interpretation of the scientific conclusion. E.g. a claim labeled as 'proven' even though it's classified as a hypothesis scientifically.

7) General confusion: Significantly misleading quotation seriously distorting the scientific claim. Supplementary to the quantitative method a qualitative analysis of three articles was carried out in order to determine the origin and nature of the inaccuracies. The qualitative analysis was especially focused on examining the anatomy of the confusions of source.

\section{Results}

As shown in Table 1, the number of news articles quoting scientific publications, the total number of news articles on climate change, and the number of scientific publications all steadily grew during the period. There's an anomaly in 2005 where news articles quoting science peaked, probably caused by a series of influential articles in Science and Nature. On the $8^{\text {th }}$ of August Science printed three separate articles refuting the otherwise acknowledged research done by climate skeptic John Christy. Two weeks earlier Nature published an article hinting that anthropogenic climate actions were to blame for hurricane Katrina. After 2005 the number of news articles quoting Science/Nature slightly declined whereas both the total number of news articles and the number of scientific publications continued rising. This development is in line with Weingart et al.'s findings from 2000 stating that the scientific discourse will be marginalized and overtaken by a political discourse. ${ }^{27}$ 
Regarding the quantitative content analysis the following were found: 46 out of the 88 articles contained a total of 70 inaccuracies.

\begin{tabular}{|llll|}
\hline Year & Articles & Articles with inaccuracies & Inaccuracies in total \\
\hline 1997 & 8 & 5 & 11 \\
1999 & 7 & 6 & 9 \\
2001 & 6 & 4 & 4 \\
2003 & 8 & 6 & 7 \\
2005 & 26 & 13 & 20 \\
2007 & 17 & 6 & 8 \\
2009 & 16 & 6 & 11 \\
Total & 88 & 46 & 70 \\
\hline
\end{tabular}

Table 2. Number of inaccuracies per year. In 1997 63\% of the news articles contained inaccuracies. In 2009 only $38 \%$ were flawed. One reason might be the increased media attention and hence journalistic specialization in climate change science.

\section{Factual inaccuracies (contained in $16 \%$ of the articles)}

It is slightly worrying that basic transcription is flawed in almost every sixth article even though most of them were minor. In one article 4,5 degrees Fahrenheit was directly translated to 4,5 degrees Celsius. In another a 3,5 degrees temperature rise were converted to 5 degrees in the news article. In others time frames were changed, for example 1980-2000 instead of the correct 1982-1999.

\section{Confusion of source (11\%)}

These are considered some of the gravest inaccuracies as peer-reviewed claims in the scientific publications were mixed with either oral statements made by the researcher or journalistic interpretation added in the popularization process. For example, in one news article from 1997 statements made by the acclaimed environmentalist Wallace Broecker in a press release was confused with written statements from his respected scientific article. For example the sentence " $\mathrm{t}]$ he results of the global warming could very well be a new ice age" is paraphrasing a press release but credited to a scientific article. However, this article does not mention the possibility of an imminent ice age.

\section{Omissions/additions (23\%)}

Expressions arbitrary to the scientific claims such as 'the warmest and wettest winter, 'polar bears' or 'human caused greenhouse effect' were added to direct or indirect quotes. Omissions mostly included leaving out geographic limitations. For example, in one article it was not specified that claims about the ozone layer were restricted to the arctic area. However none of the omissions or additions caused critical manipulation of the central claims of the scientific articles.

\section{Exaggerations (7\%)}

Most severe in this category was one article claiming that the earth would most likely heat up by 11 degrees over the next 100 year even though the probability stated in the scientific publication was below $4,2 \%$. Others included generalized claims as for example stating that the temperature has risen 5 degrees during winter time in the northern hemisphere even though the scientific claims was restricted to a few fragmented areas. In another article it was claimed that the global sea level could rise 1,4 meters within this century whereas the publication stated an uncertainty range from $0,5-1,4$ meters. 


\section{Paraphrases (2\%)}

Only two such inaccuracies were identified, suggesting that overall the Danish broadsheet newspapers use a consensus based objective vocabulary e.g. 'global warming' or 'climate change' as opposed to 'climate catastrophe'.

\section{Faulty conclusions (10\%)}

Most inaccuracies in this category included hypotheses or conclusions from preliminary studies being forwarded as solid facts, leaving out crucial modifications. For example, in a news article from 2005 it is reported as confirmed that the golf stream is significantly weakened while the corresponding scientific article only suggests that the results can be interpreted that way. In another the following is stated: "Researchers convinced: Climate changes on earth are human induced". In the scientific article it is modified: "[i]]t may be anthropogenically induced and may continue to rise".

\section{General confusion (5\%)}

Only four articles out of the 88 had serious inaccuracies causing general confusion about the scientific claims. Two were included in this category because of grave confusion of source. Another was included because of the high amount of inaccuracies and one because of the focus on the inaccurate conclusion that the earth most likely would warm 11 degrees Celsius within the next century.

According to the primary hypothesis it is surprising to find that more than half of the news articles include inaccuracies. Also the amount of confusion of source was unforeseen - it was present in $11 \%$ of the news articles. In most of these, exclusive information from press releases was credited to the scientific articles. This kind of detachment from the original scientific articles and foundation in other press material is also observable in categories such as factual inaccuracies, additions and exaggerations. Here claims were unconsciously being forwarded from secondary material without being fact checked in the scientific publication. These results are, nevertheless, in consensus with Woloshin's and Schwartz's research from 2002 stating that $82 \%$ of all scientific publications being covered in the mass media are based on press releases. $^{28}$

Based on the quantitative results, it is therefore fair to criticize the high quality newspapers for mishandling scientific claims, but the essence of the present criticism is wrong. Instead of attacking the news values or journalistic norms, the debate should both emphasize journalistic work conditions with insufficient time for thoroughness as well as the communication structure currently surrounding science news, which often lets news journalist rely on secondary sources.

Also it is worth noting that many of the news articles had problems reproducing accurate temperatures a central part of climate science news. In three articles the inaccuracy seems to stem from a lack of conversion from Fahrenheit to Celsius. In others an inaccurate temperature raise were added or an uncertainty range was omitted.

\section{Conclusions}

46 out of 88 news articles contained a total of 70 inaccuracies. Even though the majority was found to be random and seemingly unintended it is still a surprising result, especially considering that one in six included factual inaccuracies. It is therefore concluded that the selected Danish high quality newspapers were moderately inaccurate in quoting climate science from the journals Science and Nature.

Compared to both Bell's, McInerney et al.'s, Bubela and Caulfield's results this study shows a higher degree of total inaccuracies as the majority were flawed. But in line with previous research, exaggerations were neither common nor serious inaccuracies. Moreover, only four news articles could be categorized as containing general confusion. This confirms the conclusion made by McInerney et al. that only a minor fraction of news articles are distorting the original scientific claims. Therefore this study supports the scholarly founded claim that the news media does not predominantly hype science news. 
Instead, confusion of source, present in $11 \%$ of the news articles, was found to be more dominant than expected. This category is particularly interesting and should invite further examination as confusion of source confuses the relationship between peer-reviewed claims and common statements originating in press or news material. This makes it impossible for the receiver to distinguish between scientifically validated claims and unconfirmed statements or interpretations.

It is therefore proposed that a change of perception is necessary within the science community from the current dogmatic perspective on the news media as sensationalizing, dramatizing and exaggerating science to a more nuanced look on the origin and flow of science news.

\section{Discussion}

A university releases press material about research being published in Science or Nature. An international news agent like Reuters or AP transmits it into the international news flow. The Danish news agent Ritzau picks it up and soon it's in every science journalist's inbox. Science news travelling this commonly used road between lab and media therefore pass through four gatekeepers, each of them processing or translating the original material. No wonder inaccuracies happen. But as this study shows the inaccuracies themselves are not the most worrying. More importantly, leaving out the gatekeepers as source skews the popularization of science.

For the receiver of science news it is therefore legitimate to ask: Where does science news come from? As mentioned earlier, research shows that $82 \%$ stem from press releases. Furthermore K. Wilson in 2000 concluded that the majority of science reporters use news outlets as their dominant knowledge source. ${ }^{29}$ This means that the road from lab to news becomes shadowy.

Additionally, it was impossible in the analysis to determine the origin of the inaccuracies. Some were traced to a telegram, press release or other news source making it unfeasible to hold news journalists solely responsibility for miscommunicating science. Previous research has also shown that press releases as well as scientists themselves exaggerate research claims. ${ }^{30,31}$

As suggested earlier, it may be fruitful to initiate a paradigm shift in the research of accuracy in science news. News articles are only the tip of the iceberg and underneath an abundant network of communication structures each influencing and possibly alternating the scientific message is buzzing ${ }^{32}$. Only by mapping and understanding these structures comprehensively, can we improve the accuracy of science news.

\section{Acknowledgements}

The author wishes to thank her dissertation supervisors Niels Ole Finnemann and Kristian Hvidtfelt Nielsen for useful comments and Kristine Hays Lynning for reviewing the article.

\section{Notes and references}

\footnotetext{
${ }^{1}$ M. Hulme (2009), Why we disagree about climate change, Cambridge University Press, New York U.S.A. pp. $230-31$.

2 P. Broks (2006), Understanding Popular Science, Open University Press, England, pp. 59.

${ }^{3}$ M.T. Boykoff (2007), Flogging a dead norm? Newspaper coverage of anthropogenic climate change in the United States and United Kingdom from 2003 to 2006, Area 39(2).

${ }^{4}$ M. Bucchi and R.G. Mazzolini (2008), Big science, little news, science coverage in Italian daily press, 1946-1997, in M.W. Bauer and M. Bucchi (2008), Journalism, Science and Society, science communication between news and public relations, Routlegde, New York U.S.A. pp. 53.

5 B. Ward (2008), The Royal Society and the debate on climate change, in M.W. Bauer and M. Bucchi (2008), Journalism, Science and Society, science communication between news and public relations, Routlegde, New York U.S.A. pp. 163.

6 D. Nelkin (1987), Selling science, W.H. Freeman, New York U.S.A.

${ }^{7}$ R.K. Merton (1942), The Normative Structure of Science, in R.K. Merton, The Sociology of Science: Theoretical and Empirical Investigations, University of Chicago Press, Chicago U.S.A. (1973).

${ }^{8}$ P. Kramhøft (2000), Journalistik med omtanke, Forlaget Ajour, Gylling, pp. 52.

${ }^{9}$ C. McInerney, N. Bird and M. Nucci (2004), The flow of scientific knowledge from lab to the lay public: The case of genetically modified food, In Science Communication 26(44): 66.
} 
${ }^{10}$ G. Geller, B.A. Bernhardt, M. Gardner, J. Rodgers and N.A. Holtzman (2005), Scientists' and science writers' experiences reporting genetic discoveries: toward an ethic of trust in science journalism, Genet. Med. 7(3): 198-205.

${ }^{11}$ C. McInerney, N. Bird and M. Nucci (2004), The flow of scientific knowledge from lab to the lay public: The case of genetically modified food, Science Communication 26(44): 50.

12 J.W. Tankard and M. Ryan Jr. (1974), News Source Perceptions of Accuracy of Science Coverage, Journalism Quarterly 51(2): 219-225.

13 D.L. Pulford (1976), Followup Study of Science News Accuracy, Journalism Quarterly 53: 119-121.

14 P.J. Tichenor et al. (1970), Mass Communication Systems and Communication Accuracy in Science News Reporting, JournalismQuarterly 47((Winter)): 673-683.

15 Ibid.

16 R.B. McCall and S.H. Stocking (1983), Between Scientists and Public: Communication Psychological Research Through the Mass Media, in American Psychologist 37(9): 985-995.

17 A. Bell (1994), Media (mis)communication on the science of climate change, Public Understanding of Science 3(3): 259-275.

18 C. McInerney, N. Bird and M. Nucci (2004), The flow of scientific knowledge from lab to the lay public: The case of genetically modified food, Science Communication 26(44): 65.

19 J. Eldridge and J. Reilly (2003), Risk and relativity: BSE and the British media, in N. Pidgeon, R.E. Kasperson, P. Slovic (eds), The social amplification of risk, pp. 138-56, Cambridge University Press, Cambridge U.K.

20 T.M. Bubela and T. Caulfield (2004), Do the print media 'hype' genetic research? A comparison of newspaper stories and peerreviewed research papers, in Canadian Medical Association Journal, April 27, 2004, 170(9).

${ }^{21}$ D.C.Hallin and P. Mancini (2004), Comparing media systems: three models of media and politics, Cambridge University Press, Cambridge U.K

${ }^{22}$ K.H. Nielsen (2005), Between understanding and appreciation. Current science communication in Denmark, JCOM 04(04): A02.

23 R.S. Kjærgaard (2010), Making a small country count: nanotechnology in Danish newspapers from 1996 to 2006 , in Public Understanding of Science 19(1): 80-97.

${ }^{24}$ M.T. Boykoff (2007), Flogging a dead norm? Newspaper coverage of anthropogenic climate change in the United States and United Kingdom from 2003 to 2006, in Area 39(2).

${ }^{25}$ In Denmark the two tabloid newspapers Ekstrabladet and B.T only ranks as the $5^{\text {th }}$ and the $8^{\text {th }}$ most read newspapers. Tabloids are therefore not as widely read in Denmark as in most anglo-american countries. See

${ }^{26}$ D. Riffe, S. Lacy and G.F. Fico (2005), Analyzing Media Messages Using Quantitative Content Analysis in Research, second edition, Lawrence Erlbaum Associates, London U.K., pp. 68-69.

${ }^{27}$ P. Weingart, A. Engels and P. Pansegrau (2000), Risks of communication: Discourses on climate change in science, politics and the mass media, in Public Understanding of Science 9(3): 261-283.

${ }_{28}$ S. Woloshin and L.M. Schwartz (2002), Travels in the genetically modified zone, Harvard University Press, Harvard U.S.A.

29 K. Wilson (2000), Drought, Debate, and Uncertainty: Measuring Reporters' Knowledge and Ignorance about Climate Change, Public Understanding of Science 9: 1-13.

${ }^{30}$ S. Woloshin and L.M. Schwartz (2002), Press releases Translating research into news, JamaJournal of the American Medical Association 287(21): 2856-2858.

31 N.A. Holtzman et al. (2005), The quality of media reports on discoveries related to human genetic diseases, Community Genet. 8(3): 133-144.

32 B. Lewenstein (1995), From Fax to Facts: Science Communication in The Cold Fusion Saga, Social Studies of Science 25(3): 403-436.

\section{Author}

Gunver Lystbæk Vestergård has a graduate degree in Journalism, supplementary studies in Science Studies and an undergraduate degree in Media Studies from the University of Aarhus, Denmark. She is currently affiliated with the Department of Science Studies, Aarhus University. E-mail: glv@adm.au.dk.

HOW TO CITE: G.L. Vestergård, From journal to headline: the accuracy of climate science news in Danish high quality newspapers, Jcom 10(02) (2011) A03. 